\title{
ARTE, UMA NECESSIDADE HUMANA: FUNÇÃO SOCIAL E EDUCATIVA.
}

\author{
Rosane Kloh Biesdorf ${ }^{1}$ \\ Marli Ferreira Wandscheer ${ }^{2}$
}

RESUMO A arte mostra-se presente na história da humanidade desde os tempos mais remotos. Sem dúvida, ela pode ser considerada como sendo uma necessidade de expressão do ser humano, surgindo como fruto da relação homem/mundo. Por meio da arte a humanidade expressa suas necessidades, crenças, desejos, sonhos. Todos têm uma história, que pode ser individual ou coletiva. As representações artísticas nos oferecem elementos que facilitam a compreensão da história dos povos em cada período.

Palavras-chaves: arte; história; necessidade; educação.

ABSTRACT The art has been presented in the humanity history since the remote times. Can certainly, it be concidered as a necessity of expression of the human being, it appears as the fruit of the relationship man/world. Through the art humanity express your necessities, beliefs, wishs, dreams. Evereyone has a history, that can lee individual or collective. The artistic representations offer us elements that facilitate the comprehension of people history in each time.

Key-words: arts; history; necessity; education.

\section{INTRODUÇÃO}

Toda a forma de representação artística somente acontece em um ambiente em que o homem pode expressar-se por meio de suas produções. A arte também é produzida, acima de tudo, por uma necessidade de expressão, segundo Fischer (1987, p.20), “A arte é quase tão antiga quanto o homem." Nesse sentido, Duarte Júnior (1994, p. 136) complementa “A arte está com o homem desde que este existe no mundo, ela foi tudo o que restou da culturas préhistóricas." O levantamento histórico das antigas civilizações ocorre, principalmente, por meio de registros históricos que são encontrados; percebe-se assim que essas civilizações

1 Mestranda em Educação pela UFSCar, São Carlos-SP. rosane_kloh@yahoo.com.br

2 Mestranda em Educação pela UNOESC, Joaçaba-SC marlifw@yahoo.com.br. 
empregavam a arte na grande maioria de suas atividades

O ser humano se expressa por meio da arte desde os tempos mais remotos; a expressão artística é a forma que o homem encontra para representar o seu meio social. De acordo com Buoro (2000, p. 25) "Portanto, entendendo arte como produto do embate homem/mundo, consideramos que ela é vida. Por meio dela o homem interpreta sua própria natureza, construindo formas ao mesmo tempo em que se descobre, inventa, figura e conhece."

Desta maneira podemos dizer serem as invenções filhas das épocas em que acontecem, pois não há descoberta cientifica ou produção artística sem que existam condições materiais e psicológicas favoráveis ao seu aparecimento. Elas sempre se apóiam em acontecimentos anteriores, inscritos em um processo histórico. (BUORO, 2000, p. 82).

A humanidade sempre procurou adaptar-se à realidade do seu cotidiano. Os PCNs (2001, p. 21) colocam que "Desde o início da história da humanidade a arte sempre esteve presente em praticamente todas as formações culturais." Inicialmente, isso se deu muito mais por uma necessidade de adaptação, de transformação do meio em favor do homem. Buoro (2000, p. 29) destaca que "[...] no percurso da história não há civilização que não tenha produzido arte." Desde o período pré-histórico, a arte esteve presente significativamente no cotidiano do homem, conforme Fischer (1987, p.45) "Nos alvores da humanidade a arte pouco tinha a ver com "beleza" e nada tinha a ver com a contemplação estética: era um instrumento mágico, uma arma da coletividade humana em sua luta pela sobrevivência." Para o homem pré-histórico, era fundamental representar suas crenças, seus anseios, valores, hábitos, costumes, e suas necessidades por meio das representações artísticas.

Fischer (1987) destaca que a arte nunca foi uma produção de origem individual, mas sim, coletiva, se originando de uma necessidade coletiva. O ser humano se utiliza da arte para dialogar com o meio em que vive, a arte somente tem sentido quando sua representação for uma representação social. Nesse aspecto, Coli (1989, p. 90) complementa "No passado, e ainda hoje, os objetos artísticos possuíram funções sociais e econômicas que permitiram sua constituição e seu desenvolvimento."

De acordo com Ledur (2005, p. 75), “O autor da obra é portador da visão artística e do ato criador e ocupa uma posição significativa e responsável”. Esta posição significativa e 
responsável demonstra o compromisso que o artista possui frente a sua cultura, um compromisso de fazer arte com significados presentes no meio em que está inserido.

De acordo com Barbosa (1990, p. 11), “Acredita-se que a arte não é apenas uma consequência de modificações culturais, porém o instrumento provocador de tais modificações". Compreende-se, desse modo, que a arte adquire novos conceitos em cada período, modificando a forma do homem ver e pensar o mundo. Os PCNs (2001, p. 19) destacam que "[...] A arte de cada cultura revela o modo de perceber, sentir e articular significados e valores que governam os diferentes tipos de relações entre os indivíduos na sociedade." A arte no campo educacional é uma proposta capaz de provocar mudanças no modo de o aluno ver o seu meio e nele agir.

Na visão de Fischer (1987, p. 20), “A arte é necessária para que o homem se torne capaz de conhecer e mudar o mundo. Mas a arte também é necessária em virtude da magia que lhe é inerente.” Para o artista, a arte possui uma função muito maior do que simplesmente ser bela, ser agradável, decorativa, a obra é a representação do que o artista vive, pensa e sente, $o$ artista se molda em sua obra.

\section{A FUNÇÃO SOCIAL DA ARTE}

A arte por meio de suas representações procura compreender as características próprias de um momento da sociedade e é uma forma de manifestação social. O artista usa a obra para relatar o seu momento. Fischer (1987) apresenta alguns questionamentos acerca do tema, como: Será a arte apenas um substituto? Não expressará ela também uma relação mais profunda entre o homem e o mundo? E naturalmente, poderá a função da arte ser resumida em uma única fórmula? Não satisfará ela diversas e variadas necessidades? E, se, observarmos as origens da arte, chegarmos a conhecer sua função inicial, não verificaremos também que essa função inicial se modificou e que novas funções passaram a existir?

Percebe-se que a função da arte como também seu modo e os meios de representação variam conforme a época, segundo Buoro (2000, p. 23) "Em cada momento específico e em cada cultura, o homem tenta satisfazer suas necessidades socioculturais também por meio de sua vontade/necessidade de arte".

De acordo com Fischer (1987, p.51), “[...] o artista continua sendo o porta voz da sociedade." Ainda nos dias atuais o artista tem uma função social indiscutível: ser um 
representante da sociedade, relatar em suas obras a realidade pela qual ela passa. Fischer (1987, p. 51-52) ainda manifesta "A tarefa do artista é expor ao seu público a significação profunda dos acontecimentos, fazendo-o compreender claramente a necessidade e as relações essenciais entre o homem e a natureza e entre o homem e a sociedade"

Segundo Coli (1989, p. 27) "Assim, um mesmo criador pode desenvolver em sua produção tendências diferentes, que, se sucedem no tempo, constituem as "fases" distintas do artista." Um mesmo artista pode viver em diversas fases; isso devido à rápida transformação pela qual a sociedade passa, frente ao acelerado crescimento tecnológico e às transformações sociais. Coli (1989, p. 64) ainda destaca "Ora, é importante ter em mente que a idéia de arte não é própria a todas as culturas e que a nossa possui uma maneira muito específica de concebê-la." Dessa forma, o artista não poderá exigir que todos compreendam a sua obra. Esta será mais facilmente compreendida no meio social na qual está inserida, já outras culturas poderão ter dificuldades em compreendê-la.

$\mathrm{Na}$ atualidade, em meio a inúmeras tecnologias existentes, segundo Fischer (1987, p. 231), “[...] uma das grandes funções da arte numa época de imenso poder mecânico é a de mostrar que existem decisões livres, que o homem é capaz de criar situações de que precisa, as situações para as quais se inclina a sua vontade." No mundo globalizado, o homem está passando por um processo de transformação, mudando hábitos, conceitos, pensamentos, porém é indispensável que aproveite a liberdade para se expressar, e o artista, sendo livre, deve usar da liberdade para desempenhar o seu papel social.

Para Fischer (1987), a arte é a própria realidade social, é a representação do momento, e ao menos que ela queira ser infiel à sua função social, precisa mostrar o mundo como passível de ser mudado, e fazer a sua função para ajudar a mudá-lo A sociedade precisa do artista, e ele deve ser fiel e consciente de sua função social. Cabe a ele, educar a sociedade para que ela possa fazer um desfrute e uma compreensão apropriada da arte.

\section{COMPREENDER E ENSINAR ARTE NUM VIÉS SÓCIO-EDUCATIVO}

O estudo da arte em sala de aula é importante para que os educandos compreendam a arte como fruto da relação do ser humano com a sociedade em que vive, de acordo com Fuzari e Ferraz (1993, p. 63), “A criança reflete continuamente suas impressões do meio circundante [...] sua compreensão do real faz-se por meio de uma inter-relação dessas 
Revista Eletrônica do Curso de Pedagogia

do Campus Jatai = UFG

impressões com as coisas percebidas". Pela percepção e compreensão do meio, como Ferreira (2001, p. 15) apresenta "As artes são produções culturais que precisam ser conhecidas e compreendidas pelos alunos, já que é nas culturas que nos constituímos como sujeitos humanos". Somente a criança compreendendo o sentido dos seus hábitos, crenças, valores é que terá condições de os interligar às representações do homem.

Parafraseando Best (1996), reconhecendo o lugar crucial da compreensão e do conhecimento, é que podemos providenciar um cômputo inteligível da arte na educação e só assim é que poderemos verificar como é possível a liberdade individual ser expressa por meio da arte. Os sentimentos artísticos são de caráter racional/cognitivo. Não há duas coisas, mas uma só: sensibilidade racional cognitiva. Isso mostra que a arte pode ser tão completamente educacional, porque envolve a compreensão e a racionalidade como qualquer outra área curricular. Dessa forma, a arte deve ter a mesma consideração que as demais disciplinas, tanto pelos educandos como por toda a comunidade escolar.

$\mathrm{O}$ ensino da arte, compreendido pelos alunos, pais, professores e sociedade como sendo também uma disciplina importante e fundamental para a formação do aluno, de acordo com Buoro (2000, p. 36) “[...] também os pais colocam o trabalho de artes plásticas na escola em segundo plano, pois se sentem ansiosos com a alfabetização dos filhos e não sabem muito bem a finalidade das aulas de artes." É importante e indispensável que toda a comunidade escolar tenha ciência do real objetivo do estudo de artes em sala de aula, valorizando a disciplina da mesma forma que as demais.

Conforme Duarte Jr. (2003), alguns educadores entendem que o raciocínio lógico, a sensibilidade, a percepção estética estejam separados, isso está acontecendo atualmente. Raciocínio e sensibilidade nunca estiveram tão separados como agora, porém essa separação é só aparente, pois o homem é um conjunto de sentimento e razão.

O aluno ao compreender o objetivo do estudo de um tema, compreende a importância de tal aprendizagem. Para Fuzari e Ferraz (1993) não é suficiente dizer que os alunos precisam dominar os conhecimentos, é necessário mostrar-lhes o caminho, isto é, investigar os objetivos e métodos seguros e eficazes para que o educando tenha condições de assimilar os conhecimentos. O ensino somente é bem sucedido quando os objetivos do professor coincidem com os objetivos de estudo do aluno, tendo em vista o desenvolvimento das suas forças intelectuais. A finalidade do processo de ensino é proporcionar aos alunos os meios para que assimilem os conhecimentos. O trabalho docente é a mediação entre o 
educando, os métodos, a didática de ensino e o conhecimento.

De acordo com Fuzari e Ferraz (1993, p. 84), “O brincar nas aulas de arte pode ser uma maneira prazerosa de a criança experimentar novas situações e ajudá-la a compreender e assimilar mais facilmente o mundo cultural e estético." O brincar para a criança é uma forma de facilitar a compreensão do conteúdo em estudo.

Fischer (1987, p. 252) destaca "A magia da arte está em que, nesse processo de recriação, ela mostra a realidade como passível de ser transformada, dominada e tornada brinquedo". É possível estudar a arte de forma agradável, que venha a despertar no aluno o interesse para conhecer a história.

O educador necessita, segundo Fuzari e Ferraz (1993), compreender o processo de conhecimento da arte pela criança,( o que) significa mergulhar em seu mundo expressivo. Por isso, o professor precisa procurar saber porque e como a criança compreende a arte, precisa saber arte, e saber ser professor de arte junto às crianças. No encontro que se faz entre a arte e criança situa-se o professor, cujo trabalho educativo será de intermediar os conhecimentos existentes e oferecer condições para novos estudos.

O processo do ensino e aprendizagem da arte não ocorre apenas na educação formal. Para Best (1996, p. 52), “A educação não está, de modo nenhum, limitada ao que acontece nas escolas, colégios e universidades. Há muito que aprender com as artes, ao longo de uma vida.” A arte está presente em diversos ambientes, em alguns momentos de forma explícita, em outras subjetivamente". O estudo da arte é necessário, segundo Ferreira (2001, p. 15), "No meu entender, o motivo mais importante para incluirmos as artes no currículo da educação básica é que elas são parte do patrimônio cultural da humanidade, e uma das principais funções da escola é preservar esse patrimônio e dá-lo a conhecer." O educando reconhecerá e respeitará a arte se conhecer o seu valor para a sociedade. Não se pode exigir que uma pessoa respeite o que lhe é desconhecido; a arte é cultura de uma sociedade e cabe à escola ensinar a história, os valores e significados dessa cultura.

O ensino da arte somente fará sentido ao educando se (ele) conhecer e reconhecer a importância que o estudo terá no seu cotidiano. Para Best (1996, p. 19), “Tem que haver um relacionamento, de longe mais rico, entre a pessoa e o trabalho artístico, para que faça sentido a educação por meio da arte e para que faça sentido a idéia de uma realização progressiva da realidade individual.” A arte poderá até ser uma criação individual, porém a obra somente surgirá devido a fatores sociais que lhe dão origem, fatores esses que deverão ser 
reconhecidos em todas as formas de representação da arte.

\section{A FINALIDADE DA ARTE NA EDUCAÇÃO}

O ensino de artes na educação básica é necessário para o desenvolvimento da capacidade reflexiva, criativa e crítica do aluno, bem como para despertar nele saberes sensíveis para com a sociedade em que vive. Segundo Buoro (2000), a finalidade da arte na educação é contribuir na formação de indivíduos mais críticos e criativos, que atuarão na transformação da sociedade.

A Arte no século XIX, passou a ser estudada pelas ciências humanas como objeto da educação. Na época, alguns pensadores criaram o DBAE (Diciplines Based Arte Educacion), proposta de ensino que estudou de forma integrada a produção, a crítica, a estética e a história da Arte. No Brasil, a adaptação do DBAE foi feita pela professora Ana Mae Barbosa em 1978.

Conforme os PCNs (2001, p. 28) "Em 1971, pela Lei de Diretrizes e Bases da Educação Nacional (LDB), a arte é incluída no currículo escolar com o título de Educação Artística, mas é considerada "atividade educativa" e não disciplina." passando a ser considerada disciplina apenas alguns anos mais tarde Desde que foram inseridas na educação básica como disciplina, as artes sofreram inúmeras transformações. Knoener (2006, p. 25) destaca que "A Arte passa a ser valorizada pelo DBAE como objeto do saber, com base na construção, na elaboração e na organização desse saber, acrescentando à dimensão do fazer a possibilidade de apreciar e de entender o patrimônio artístico cultural da humanidade." A tarefa do arte-educador é a de realizar a mediação entre o conhecimento de arte e o educando, preparando-o para a expressão e reflexão da arte na sua relação com a sociedade, como destaca Knoener (2006, p. 26)

\footnotetext{
Hoje, duas coisas que ocorrem com a teoria e a prática da arte-educação no Brasil nos chamam a atenção. Vemos, por um lado, uma dicotomia entre a prática do arteeducador em sala de aula e o que deveria ser uma compreensão do campo da arte como um todo, sua relação com a história e com a sociedade. O papel transformador e crítico da arte como forma de expressão e de reflexão do homem e da sociedade na história parece estar ausente, ou ocupa um papel menor nas discussões em pauta.
}

A Proposta curricular de Santa Catarina (1998, p. 197) define que "Conhecer a 
história da arte e os estilos artísticos pode ser de grande utilidade para que se conheçam certas inquietações que os artistas abordam. É importante considerar que o que as pessoas dizem a respeito de uma imagem. Dessa forma, percebe-se a real importância do ensino da história da arte. Toda obra para ser compreendida precisa ser situada em seu período histórico, pois é uma representação de uma época, de uma realidade, de um pensamento.

Para Ferreira (2001, p. 12), “[...] as artes devem estar presentes no currículo escolar não por suas contribuições nesses campos de desenvolvimento, mas pelos benefícios que apenas as artes, e nenhuma outra área de estudo, podem oferecer à educação". Nesse aspecto Porcher (1982, p. 30) complementa que “[...] Não há duvida de que a prática das atividades artísticas representa um fator altamente favorável para o desenvolvimento de toda a personalidade e, especialmente, dos seus aspectos intelectuais". A arte deve ser considerada e valorizada como disciplina presente na escola, pois, além de estudar suas manifestações e sua história, é fundamental para o desenvolvimento da criatividade, da sensibilidade do educando. Bouro neste aspecto complementa:

O objetivo geral dessa proposta de ensino de artes plásticas na escola, é desenvolver no aluno a percepção visual do mundo e da obra de arte, ampliando seu repertório visual e gráfico, contribuindo para a construção de um olhar critico no exercício de sua cidadania. (BUORO, 2000, p.16)

Frequentemente o artista se utiliza da arte para fazer uma crítica a um fato; sua obra somente será compreendida se o espectador estiver preparado para esta leitura. Ferreira (2001) destaca que ao conhecerem e praticarem as artes, assim como a ciência, os alunos poderão entender que as primeiras são formas diferentes de dizer e compreender o mundo, e que aquilo que se diz pela arte não pode ser dito pelas ciências. Também poderão entender as diversas linguagens da arte, como a dança, a música, o teatro, as artes visuais (e) que cada uma delas poderá revelar algo, um sentido, um sentimento. Entenderão a relação existente entre aquilo que se deseja expressar com a linguagem utilizada para esse fim. A autora ainda enfatiza que outra contribuição das atividades artísticas é que elas podem ajudar os alunos a desenvolver um pensamento mais flexível, menos cristalizado, porque, no processo de criação, é comum iniciar-se um projeto com determinado propósito que, no decorrer da ação, é trocado por outro, a fim de explorar uma oportunidade inesperada, aproveitando-se, assim, os acasos do processo de criação artística. Nesse sentido, Best (1996, p. 7), nos diz que "A poderosa possibilidade de aprendizagem a partir da arte é clara, ainda que de forma 
implícita." Desta forma, é necessário levar-se em consideração os inúmeros benefícios que as artes trazem ao educando, e não apenas a produção em Artes especificamente.

À medida que passam a dominar técnicas que lhes possibilitem manejar esses elementos para conceituar e expressar idéias, os alunos ficam mais confiantes, porque se tornam mais habilidosos e competentes no campo das artes. A confiança em si mesmo é elemento importante na construção da auto-estima, e esta pode ser mais uma das justificativas para trabalhar com artes na escola. (FERREIRA 2001, p. 24)

Segundo Barbosa (1990, p. 90), “[...] antes de ser preparado para explicar a importância da arte na educação, o professor deverá estar preparado para entender e explicar a função da arte para o indivíduo e para a sociedade". O professor necessita ter a compreensão da importância da arte para dessa forma conscientizar os educandos e a sociedade.

Para Fuzari e Ferraz (1993), as aulas de arte constituem-se de espaços onde as crianças podem exercitar suas potencialidades perceptivas, imaginativas ou fantasiosas. A expressão infantil é a manifestação imaginativa, sentimental, do cotidiano das crianças. Desde bem pequenas, elas vão desenvolvendo uma linguagem própria, traduzida em signos e símbolos carregados de significação subjetiva.

$\mathrm{O}$ arte-educador tem o compromisso de desenvolver seu trabalho junto ao educando e à comunidade escolar, de forma que todos compreendam o verdadeiro papel das Artes. Como diz Ferreira (2001, p. 11), "Na opinião de muitos professores, as artes têm um caráter utilitário, meramente instrumental. O desenho, por exemplo, serviria para "ilustrar os trabalhos de português, ciências, geografia”. Dessa forma, cabe ao educador transformar esse pensamento, mostrando o verdadeiro sentido do estudo da arte na escola.

A escola é um ambiente que permite ao aluno compreender a arte como sendo uma forma de expressão do seu universo: a arte infantil é fruto das vivências infantis, já a arte do adulto é fruto da relação e compreensão que ele possui de todo o meio que o circula.

[...] é a concepção de que a criança é muito mais inventiva que o adulto [...], esse ultimo apresenta potencial criativo desenvolvido e repertorio acumulado pelas experiências vividas, sendo capaz de ativar esse potencial e repertorio em situações especiais, transformando-se e mudando o mundo. A criança normalmente ainda não transforma a realidade, apenas a si mesma. (BUORO, 2000, p. 84). 
A representação plástica da criança é parte importante da proposta educacional e passa por todo um processo de registro que nasce na garatuja e vai em direção a um desejo de representação cada vez mais próximo da realidade; os desenhos das crianças são o resultado de sua compreensão de mundo.

O professor tem papel fundamental na formação dos indivíduos. Para Fuzari e Ferraz (1993, p. 34) “A educação escolar deve assumir, através do ensino e da aprendizagem [...] a responsabilidade de dar ao educando o instrumental para que ele exerça uma cidadania mais consciente, crítica e participante."

Segundo Barbosa (1990), o papel da arte na educação é grandemente afetado pelo modo como o professor e o aluno vêem o papel dela fora da escola, o professor precisa compreender qual o seu papel junto à comunidade educacional. Cabe a ele, transformar a atual visão que se tem da disciplina de Artes. Ainda, para Barbosa (1990, p.46), "Todos os professores de arte sabem da necessidade de estudar e conhecer a teoria da percepção, a criatividade, a antropologia, a sociologia e a estética, mas poucos são os realmente empenhados nisso." O educador tem o compromisso de oferecer ao educando experiências que lhe permitam compreender a arte como elemento presente em seu cotidiano, como elemento em que os desejos e a criatividade se unem em uma representação, pois como coloca Best (1996, p. 48), “As artes são emocionalmente criativas.”

\section{REFLEXÕES FINAIS}

Pretendeu-se, através do presente estudo, pesquisar acerca da necessidade da arte para o ser humano, para assim obter-se uma melhor compreensão sobre a sua representação e significação, como também sobre os desafios da docência em artes na atualidade. A arte sendo fiel as suas significações sempre representará o homem em sua relação com o mundo, estando este eternamente em evolução.

As atividades vivenciadas em artes proporcionam ao educando o desenvolvimento da criatividade, tornando-o um ser crítico, pensante e atuante. Somente assim se tornará cidadão ativo na sociedade em que estiver inserido, participante na transformação da sociedade.

\section{REFERÊNCIAS}




\section{Zthmerarius Reflectionis}

BARBOSA, Ana Mae. Tópicos Utópicos. Belo Horizonte: Com Arte, 1998

BEST, David. A racionalidade do sentimento: o papel das arte na educação. Portugal: Porto Codex, 1996.

BUORO, Anamelia Bueno. O olhar em construção: uma experiência de ensino e aprendizagem da arte na escola. $4^{\circ}$ edição. São Paulo: Cortez, 2000.

COLI, Jorge. O que é arte. 10 edição, São Paulo: Brasiliense. 1989

DUARTE JÚNIOR, João Francisco. Fundamentos estéticos da educação. 3. ed. Campinas: Papirus, 1994.

FERREIRA, Sueli. $\mathbf{O}$ ensino da artes: construindo caminhos. $3^{\circ}$ edição, Campinas: Papirus, 2001.

FISCHER, Ernest. A necessidade da arte. 9. ed. Rio de Janeiro: Guanabara Koogan, 1987. $254 \mathrm{p}$.

FLEURI, Reinaldo Matias. Educar para que? Contra o autoritarismo da relação pedagógica na escola. $7^{\circ}$ edição. São Paulo: Cortez, 1994.

FUZARI, Maria Helismina; FERRAZ, Maria Heloisa. Metodologia do ensino da arte. São Paulo. Cortez, 1993, $2^{\circ}$ edição. 135p.

GREIG, Philippe. A criança e seu desenho: o nascimento da arte e da escrita. Porto Alegre: Artmed, 2004.

KNOENER, Sandra Heinz. O ensino das Artes na escola: a ótica dos professores de Educação Infantil. 2006. 74 p. Dissertação (mestrado em educação) Joaçaba: UNOESC, 2006. Disponível em: http://www.unoescjba.edu.br/files-geral/meducacao/sandra-heinzknoener.pdp. Acesso em: 14 de set. De 2009.

LEDUR, Rejane Reckziegel. Professores de Arte e Arte Contemporânea: contextos de produção de sentido. 2005. 166 p. Dissertação (mestrado em educação) Porto Alegre: UFRGS 2005.

Disponível em http://www.lume.ufrgs.br/bitstream/handle/10183/5086/000509836.pdf?sequence=1 Acesso em: 09 de set. De 2009.

PORCHER, Louis. Educação artística: Luxo ou necessidade. $3^{\circ}$ edição, São Paulo, Summus, 1982

SANTA CATARINA, Secretaria de Estado da Educação e do Desporto. Proposta curricular de Santa Catarina: Educação Infantil, Ensino Fundamental e Médio: Disciplinas Curriculares. Florianópolis: Cogen, 1998. 